\title{
O CASO ARAGUAIA: OS DESAPARECIMENTOS FORÇADOS NO BRASIL
}

\author{
THE ARAGUAIA CASE: FORCED DISAPPEARANCES IN BRAZIL
}

\author{
Vivianny Kelly Galvão * \\ Lívia Bandeira Calheiros**
}

Data de recebimento: 01/02/2015

Data da aprovação: 18/06/2015

\section{RESUMO}

O Estado está proibido de esquecer. As investigações acerca das mortes e desaparecimentos forçados são passos necessários no caminho de volta à democracia. Ao analisar o caso Gomes Lund, e outros contra a República Federativa do Brasil, julgado pela Corte Interamericana de Direitos Humanos, o direito à memória surge no contexto do direito internacional dos direitos humanos. $\mathrm{O}$ direito à memória, no Caso Lund, traduz-se em crítica contundente à justiça de transição adotada pelo Brasil, mas, positivamente, reforça a ideia de soberania estatal relativizada em matéria de direitos humanos, além de legitimar a existência cada vez mais imprescindível dos órgãos com jurisdição internacional. Foram aplicadas as metodologias qualitativa e quantitativa, e com destaque, o método de abordagem indutivo e o método de procedimento histórico.

* Doutoranda pela Universidade Federal da Paraíba (2011-). Mestra em Direito Público pela Universidade Federal de Alagoas (20082010). Graduada em Direito pela Universidade Federal de Alagoas (20032008). Atua, principalmente, com as seguintes temáticas: Direito internacional, Direito internacional dos Direitos Humanos, Multicultarismo e Identidade.

E-mail: viviannygalvao@hotmail.com

** Advogada. Graduada em Direito pela Centro Universitário Tiradentes - UNIT. E-mail: liviabcalheiros@gmail.com 


\title{
PALAVRAS-CHAVE
}

Direito à memória. Direitos Humanos. Desaparecimentos forçados.

\begin{abstract}
The State is forbidden to forget. Investigations about the killings and enforced disappearances are necessary steps on the way back to democracy. By analyzing the case of Gomes Lund and others against the Federal Republic of Brazil, judged by the Inter-American Court of Human Rights, the right to memory arises in the context of international human rights law. The right to memory in case Lund translates into scathing critique of transitional justice adopted by Brazil, but positively it reinforces the idea of relativized state sovereignty in matters of human rights, and legitimates the increasingly indispensable existence of organs with international jurisdiction. The qualitative and quantitative methodologies, and particularly, the inductive method of approach and the historical method of procedure were applied.
\end{abstract}

\section{KEYWORDS}

Right to memory. Human Rights. Enforced disappearances. 


\section{INTRODUÇÃO}

No poema do austríaco Rainer Maria Rilke, Hannah Arendt, encontra-se a sutileza e a objetividade para explicar a transformação da ideia acerca de imortalidade humana sustentada no pensamento grego clássico. As linhas seguem assim (ARENDT, 2012, p. 61): “As montanhas repousam sob um esplendor de estrelas, mas nelas também cintilam o tempo. Ah, no meu coração selvagem e sombrio, a imortalidade dorme sem abrigo" (tradução livre) ${ }^{1}$. Os versos de Rilke mostram a atuação do tempo sobre todas as coisas e, sobretudo, revelam o único lugar onde a imortalidade pode habitar, dentro do coração do (finito) ser humano. Somente lá o tempo não teria poder algum sobre a duração das coisas.

O tempo cintila a mortalidade humana, mas, o desejo de se uniar à imortalidade da natureza faz com que o ser humano recorra à mãe de todas as musas, Mnémosyne. No pensamento grego, a história não era impulsionada pela força humana e sim pelo próprio movimento da natureza, logo, se tal como a natureza o ser humano era algo eterno, ele prescinderia da memória para existir. A glória das prodigiosas vitórias gregas não brilhariam através dos séculos se Hérodoto não tivesse pensado na importância da lembrança desses feitos para a posteridade. O ser para eternidade (être-à-jamais) do ser humano se realiza nos atos, nas obras, nas ações e nas palavras. A história passa a ser construção humana e a memória sua principal ferramenta.

A reconstituição do Estado e das comunidades após os crimes em massa, por exemplo, precisam levar em conta a forma como a violência ficou representada na memória do grupo. Os discursos oficiais a respeito das violações aos direitos humanos podem representar um insulto a essa memória social. Evidentemente, esquecer ou lembrar jamais será um processo linear. Há uma série de subjetivismos inerentes à memória, por isso, desde já revelamos ao leitor que não há qualquer intenção de adentrar nessa seara. Aqui, será analisado o papel do Estado, sob a perpectiva do direito internacional, na tentativa de proteger a memória. Na verdade, trata-se muito mais do dever do Estado de compor as lembranças de fatos sangrentos gerados por ele próprio. O direito à memória, nesses casos, ultrapassa questões legais (leis de anistias etc.), temporais (um novo regime não exime os atos praticados durante regimes anteriores) e, principalmente, domésticas (há clara flexibilização da noção de soberania em favor da proteção do ser humano).

\footnotetext{
${ }^{1}$ Les montagnes reposent sous une splender d'étoiles, mais en eles aussi scintille le temps. Ah, dans mon coeur sauvage et sombre, l'immortalité dort sans abri. (Tradução livre das autoras)
} 
Para quem é afeito a certo grau de otimismo e esperança no direito, além de espírito humanístico, é válido lembrar que sempre quando entramos no campo dos direitos humanos, a pessoa humana sai da posição de mero objeto normativo para assumir a posição de sujeito de direito internacional, titular de poderes e capacidades (direitos subjetivos) ante os Estados. Por romper o modelo hermético das relações internacionais interestatais, a posição do ser humano como sujeito de direito internacional faz, de fato, parecer que o ramo do direito internacional dos direitos humanos (DIDH) caminha mais avant guard que os demais.

$\mathrm{O}$ direito à memória insere-se nos espaços de proteção dos direitos humanos e representa o dever do Estado de prestar contas a seu passado mais obscuro e saldar as dívidas morais com seus cidadãos. $\mathrm{O}$ desejo que as vítimas ou familiares das vítimas possuem de moldar o discurso oficial do Estado sobre tais fatos ocorridos nestes períodos de pouca "clareza democrática" encontra-se englobado no direito à memória. Os discursos oficiais acerca dos massacres também molda a forma como a história é escrita. As referências históricas ainda são grandes aliadas dos humanistas, por isso o negacionismo histórico tem sido combatido pelos tribunais nacionais.

Este texto tem o objetivo de analisar o caso Gomes Lund, e outros contra a República Federativa do Brasil, julgado pela Corte Interamericana de Direitos Humanos, a partir das reflexões acerca do direito à memória no contexto do direito internacional dos direitos humanos. $\mathrm{O}$ caso Lund abre caminho para reflexões transversais a respeito da proteção dos direitos humanos, do direito frente à justiça de transição e a punição das violações em massa pelo sistema internacional.

\section{O BRASIL E A PRESTAÇÃO DE CONTAS COM O PASSADO}

Na prestação de contas com seu passado de exceção, o Estado está proibido de esquecer. As investigações acerca das mortes e desaparecimentos forçados são passos necessários no caminho de volta à democracia. A justiça de transição corresponde aos atos praticados pelo governo após períodos de regimes autoritários a fim de produzir o sentimento de justiça na população. Geralmente, as leis de anistia surgem com esse propósito. Na América Latina a justiça de transição está na pauta do dia. Contudo, em essência, ela já cumpriu seu ciclo vital.

Sob a bandeira do combate ao comunismo, diversas ditaduras emergiram na América Latina. Apesar de possuírem em comum um governo militar, cada Estado apresentou particularidades. Há livros como Veias Abertas da América Latina de Eduardo Galeano ([s.d], p. 9-10) que tentam explicar o contexto da América Latina 
como um todo. Sem dúvida, é empreitada bastante desafiadora diante das tantas realidades das ditaduras latino-americanas. Geralmente, como ocorre com Veias Abertas da América Latina, o discurso utilizado pelo autor é bem mais uma escolha política que uma atividade meramente descritiva de eventos passados.

A abordagem propriamente histórica do período ditatorial castrense brasileiro é recente (FICO, 2014). Primeiramente, os acontecimentos durante tal período foram narrados sob uma ótica mais direcionada à Ciência Política, com a politologia. Somente depois, o gênero memorialístico passou a se sobressair, porém, consistia em um conjunto de versões sobre a ditadura militar narrado principalmente por membros do Exército.

Duas correntes históricas emergem na tentativa de explicar o golpe militar de 31 de março de 1964. De um lado, a corrente marxista indica como fator primordial para a eclosão do golpe o caráter econômico, que possui como significativo expoente Jacob Gorender e, do outro, a corrente moderna preza pela neutralidade do historiador e aduz que o golpe militar foi causado pelos próprios militares que realizaram o golpe em causa própria (FICO, 2014). Destoante das demais, todavia mais factível, é a análise feita por Gláucio Ary Dillon Soares, para o qual o golpe dos militares teve como fatores preponderantes I) motivação econômica; II) eclosão de regimes militares na América Latina; III) militarista em essência, independente do apoio recebido. Logo, tratou-se de uma conspiração militar com o apoio dos grupos econômicos brasileiros e não o contrário, no qual os militares preocupavam-se com a má gestão administrativa e a desordem pública, o perigo da esquerda no geral, bem como o desrespeito à hierarquia militar.

Durante o período ditatorial, existiram duas espécies de censura, quais sejam: censura de imprensa e das diversões públicas. A primeira era tida como "revolucionária" nos termos de Carlos Fico, ou seja, não havia qualquer respaldo legal para a sua validade, atingindo seu ápice de efetivação durante o auge da repressão. A segunda era legalizada e objetivava a proteção da "moral e dos bons costumes", sendo praticada por funcionários especialistas. Esta última modalidade de censura era direcionada aos produtores de arte em geral, bem como aos jornalistas e teve como momento de apogeu nos final da década de 70, durante a fase de "abertura" do regime político (FICO, 2014).

Depreende-se dos atuais textos históricos que mesmo antes de 1968 já havia a prática recorrente de torturas e de censuras implementadas pelos militares aos subversivos. Tanto os generais e oficiais quanto os militares da mais baixa patente praticavam torturas e homicídios políticos. A causalidade do golpe militar de 1964 
passaria por aspectos macroestruturais e micrológicos, impulsionado pela transformação e pelo amadurecimento do capitalismo, inserido no governo frágil e instável de João Goulart. Os Atos Institucionais editados pelos dois primeiros presidentes, Castelo Branco e Costa e Silva, possuíam aspectos reformistas, demonstrando uma preocupação em legitimar os atos praticados durante o período ditatorial.

A constitucionalização formal da repressão está visível no Ato Institucional

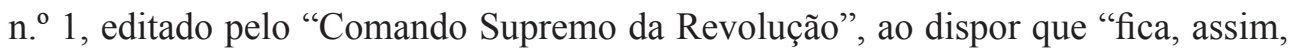
bem claro que a revolução não procura legitimar-se através do Congresso. Este é que recebe deste Ato Institucional, resultante do exercício do Poder Constituinte, inerente a todas as revoluções, a sua legitimação" (BRASIL, 2014). A partir de então, era permitido aos membros legitimados pela ditadura cassar mandatos, suspender direitos políticos, intervir em sindicatos, expurgar militar e efetuar prisões, iniciando com a política de neutralização aos opositores do regime ora imposto. O Ato Institucional n. ${ }^{\circ} 2$, editado em outubro de 1965 , extinguiu todos os partidos políticos, conforme seu artigo $18^{2}$ e estabeleceu o bipartidarismo legal com a criação da Arena (Aliança Renovadora Nacional) e do MDB (Movimento Democrático Brasileiro). Foi ampliada de forma ilimitada a discricionariedade administrativa do Executivo, culminando na desarticulação do Congresso Nacional.

A "doutrina da segurança nacional" atinge o seu apogeu com a outorga da Constituição Federal Brasileira de 1967, a edição da Lei de Segurança Nacional, bem como a Lei de Imprensa. Em seguida, o Ato Institucional n. 5 em 13 de dezembro de 1968 suspendeu o habeas corpus para crimes políticos, bem como sublimou os próprios direitos políticos. Nos termos do artigo $5^{\circ}$ do Ato ${ }^{3}$, o "Presidente da República, ouvido o Conselho de Segurança Nacional e sem as limitações previstas na Constituição, poderá suspender os direitos políticos de quaisquer cidadãos pelo prazo de 10 anos e cassar mandatos eletivos federais, estaduais e municipais.”

\footnotetext{
${ }^{2}$ Art. 18 - Ficam extintos os atuais Partidos Políticos e cancelados os respectivos registros. Parágrafo único - Para a organização dos novos Partidos são mantidas as exigências da Lei nº 4.740, de 15 de julho de 1965, e suas modificações.

${ }^{3}$ Art. $5^{\circ}$ - A suspensão dos direitos políticos, com base neste Ato, importa, simultaneamente, em: I - cessação de privilégio de foro por prerrogativa de função; II - suspensão do direito de votar e de ser votado nas eleições sindicais; III - proibição de atividades ou manifestação sobre assunto de natureza política; IV - aplicação, quando necessária, das seguintes medidas de segurança: a) liberdade vigiada; b) proibição de frequentar determinados lugares; c) domicílio determinado, $\S 1^{\circ}$ - $\mathrm{O}$ ato que decretar a suspensão dos direitos políticos poderá fixar restrições ou proibições relativamente ao exercício de quaisquer outros direitos públicos ou privados. $\S 2^{\circ}$ - As medidas de segurança de que trata o item IV deste artigo serão aplicadas pelo Ministro de Estado da Justiça, defesa a apreciação de seu ato pelo Poder Judiciário.
} 
Conforme ensina Rodrigo Santa Maria Coquillard Ayres (2014), “o endurecimento da ditadura militar, dialeticamente, provocou a radicalização da resistência", uma vez que, toda e qualquer manifestação passou a ser reprimida pelos militares da ditadura. Assim, os que se rebelavam contra o sistema vigente de forma pacífica eram torturados, subsistindo unicamente, como forma de resistência ao regime, as guerrilhas armadas e organizadas, em sua maioria, por dissidentes dos partidos políticos extintos.

Nos casos de violações aos direitos humanos em períodos de regimes autoritários, a história exerce papel essencial porque faz renascer os sentimentos de injustiça com intensidade semelhante a do instante em que tais fatos aconteceram. As lembranças afetivas da vida e da existência daquele ente desaparecido por força da ação do Estado preenchem a essência do direito à memória em direitos humanos e essa memória passa a compor a memória do próprio Estado. A memória do Estado é a memória da comunidade e, de modo positivo, esse silogismo acerca da memória contribui para afastar a visão hegeliana de Estado. Visão majoritariamente aplicada, mas incompatível com os movimentos de empoderamento do ser humano na ordem internacional.

A palavra comunidade assume lugar diferenciado. Embora Estados como o Brasil sejam formados por uma população (elemento demográfico), o direito à memória em direitos humanos fundamenta-se na identidade humana, ligando a todos, como em comunidade. Relembrar os atos de violência estatal em épocas antidemocráticas significa implementar ações cujo principal objetivo seja sempre a proteção da ideia de direitos humanos. Afora as questões técnicas acerca dos direitos humanos, não se deve olvidar o fato de eles constituírem as ideologias dominantes na sociedade internacional, na grande parte dos Estados e das comunidades. São como "fatos do mundo" incorporados à cultura.

Ao vermos violações a direitos humanos podemos ficar tristes, rechaçá-las, darmos nossas opiniões a respeito, etc. Além disso, reconhecemos a existência de grupos e movimentos defensores dos direitos humanos e, diante dos fatos, podemos criticá-los, unirmo-nos a eles, etc. E, ainda, valoramos os comportamentos utilizando os direitos humanos como estandartes. Esses são exemplos que fazem dos direitos humanos fatos do mundo. Eles formam nossa visão de mundo, pois guiam o modo de valorar aspectos importantes da vida (pessoais, sociais e políticos). A criação das Nações Unidas e dos sistemas regionais, a exemplo da OEA (Organização dos Estados Americanos), foi o principal marco do fenômeno dos direitos humanos, afinal, ela surgiu com o propósito de criar uma comunidade planetária. 


\section{A GUERRILHA DO ARAGUAIA: A RESPOSTA DO BRASIL E AS PERGUNTAS DA COMUNIDADE INTERNACIONAL}

Após o Golpe de 1964, especialmente a partir em 1968, os militares comunistas passaram a viver de forma clandestina, figurando na lista dos inimigos do Estado (SOUZA, 2007). Neste momento, os partidos políticos de esquerda desempenharam papel fundamental como força de resistência à repressão. Em meados de 1966, membros do Partido Comunista Brasileiro começaram a organizar um grupo de resistência rural à ditadura militar, objetivando manterem-se em segurança, tendo em vista que estavam sendo duramente perseguidos pelos militares. O local escolhido foi a região conhecida como Bico de Papagaio, localizada à margem esquerda do rio Araguaia, no sul do Estado do Pará (BRASIL, 2011). Liderados por Maurício Grabois, um dos expulsos da Escola Militar do Relâmpago/RJ, iniciavam-se os eventos que desencadeariam a Guerrilha do Araguaia no entorno de Marabá.

Em 1972, cerca de 90 (noventa) pessoas formavam o grupo, dentre elas, militantes do PCdoB e camponeses. No interregno entre os anos 1972 e 1975, as Forças Armadas Brasileiras realizaram nove investidas no sul do Estado do Pará até o extermínio da guerrilha, com a força de aproximadamente 4.000 (quatro mil) agentes. Com o Depoimento do ex-oficial da Aeronáutica, Pedro Corrêa Cabral, ao Ministério Público Federal, em 1974, tomou-se conhecimento de que cerca de 70 pessoas (militares e camponeses) haviam desaparecido em uma verdadeira "operação limpeza", mais da metade dos desaparecidos forçados estavam sob custódia estatal antes de serem executados (BRASIL, 2011). Em 1995, As famílias dos desaparecidos na Guerrilha do Araguaia denunciaram o Brasil à Comissão Interamericana de Direitos Humanos por violação ao Pacto de São José da Costa Rica (direito à vida, à integridade física, à liberdade pessoal, bem como a garantia da proteção dos direitos humanos e a promoção de meios internos para apuração das violações aos direitos humanos).

A falta de diligência por parte do Brasil foi o argumento acolhido pela Comissão Interamericana de Direitos Humanos. Como sempre, as ONGs exerceram papel fundamental na denúncia, a saber: o Centro pela Justiça e o Direito Internacional e do grupo Tortura Nunca Mais e a Comissão de Familiares de Mortos e Desaparecidos de São Paulo. A denúncia levou treze anos para ser enviada da CIDH à Corte Interamericana (CoIDH) e, em março de 2009, o Brasil figurava o polo passivo da ação internacional. Viviana Krsticevic e Beatriz Affonso (BRASIL, 2011, p. 364) analisaram as fases do caso Gomes Lund. 
(i) a tentativa de solução amistosa entre as partes impulsionada pela Comissão em 1996. O Estado se recusou a negociar quando os peticionários condicionaram o acordo à consideração integral das necessidades dos familiares e da sociedade como um todo pelo direito à verdade histórica; (ii) a realização de audiências na CIDH com a presença dos representantes e familiares das vítimas em 1997 e 2001, quando finalmente o caso foi admitido; (iii) o encaminhamento, cinco anos depois, das alegações finais dos representantes das vítimas, solicitando que a CIDH analisasse o mérito do caso e emitisse seu Relatório Final; (iv) a realização, perante a CIDH, de uma audiência temática em outubro de 2008. A audiência foi solicitada pois os representantes entenderam que era necessário esclarecer as consequências da Lei de Anistia no Brasil e sensibilizar o governo e os administradores de justiça a respeito da jurisprudência internacional pacífica do direito à verdade e do direito à justiça.

A CIDH aprovou Relatório Final do Caso Guerrilha do Araguaia vs. Brasil, no sentido de determinar a responsabilidade internacional brasileira, em decorrência da detenção arbitrária, tortura e desaparecimento forçado das vítimas. Outro ponto importante foi a interpretação extensiva da Lei de Anistia, no que tange o manto de legalidade jogado sobre os atos dos agentes representantes da ditadura, considerada violação severa às normas trazidas na Convenção Interamericana de Direitos Humanos. O Estado brasileiro não implementou as recomendações da Comissão, por esta razão, o caso foi remetido à Corte Interamericana de Direitos Humanos (BRASIL, 2011, p. 365).

Para a Corte Interamericana, a Lei de Anistia brasileira, responsável pelo acobertamento dos crimes cometidos pelos agentes a serviço da ditadura, "viola vários tratados internacionais e não possui nenhum valor jurídico, sobretudo o efeito de acobertar os abusos cometidos pelos agentes do Estado, durante a ditadura militar" (GOMES; MAZZUOLLI, 2011, p. 51). O Caso da Guerrilha do Araguaia apresenta clara violação ao processo denominado de justiça de transição. O Brasil foi condenado pela violação: I) ao reconhecimento da personalidade jurídica; II) à vida; III) à integridade e à liberdade pessoais que se encontram previstos nos artigos 3, 4, 5 e 7 da Convenção Americana, respectivamente, e ainda IV) aos direitos à garantias judiciais, V) liberdade de pensamento e expressão, e VI) proteção judicial ferindo os artigos 8,13 e 25, previsto no artigo 1.1, pertinente a obrigação geral de respeito e garantia dos direitos humanos, e 2, referente ao dever de adotar disposições de direito interno da mesma Convenção.

A ausência de esclarecimentos sobre os desaparecimentos de pessoas por 
parte do Estado brasileiro viola o direito à memória em direitos humanos. O silêncio dos fatos sem a entrega dos documentos relativos aos desaparecidos demonstra a inércia do Estado diante do dever de se retratar por atos do seu passado obscuro que geraram sofrimento aos seus cidadãos. Os desaparecimentos forçados configuram crime contra a humanidade, transcendendo a história. Os atos de violência foram "perpetrados pelas forças de segurança do governo militar, nos quais os agentes estatais [...] utilizaram a investidura oficial e recursos outorgados pelo Estado para fazer desaparecer a todos os membros da Guerrilha do Araguaia" (CORTE INTERAMERICANA DE DIREITOS HUMANOS, 2010, P. 30). A Corte Interamericana de Direitos Humanos ainda sugeriu a criação de marco normativo para tipificar como delito autônomo o desaparecimento forçado de pessoas.

No mais, a Corte reiterou procedimentos anteriores no sentido de que a obrigação de investigar violações de direitos humanos encontra-se dentro das medidas positivas que os Estados devem adotar para garantir os direitos estabelecidos na Convenção, salientando ser imprescindível a apuração, investigação e, caso haja a conformidade da hipótese fática com a norma hipotética, a punição dos agentes a serviço da ditadura que praticaram atos de tortura. Com base no direito à memória em direitos humanos, torna-se, portanto, insustentável que a Lei da Anistia represente obstáculo à investigação dos desaparecimentos forçados, fatos ocorridos no contexto da guerrilha do Araguaia, identificação e punição daqueles que cometeram crimes contra a humanidade ${ }^{4}$.

Ao tempo da sentença da CoIDH, o Supremo Tribunal Federal havia (meses antes, abril de 2010) julgado a ADPF ${ }^{\circ} 153$, ajuizada pelo Conselho Federal da $\mathrm{OAB}$ do Brasil a fim de verificar a abrangência da Lei da Anistia. Em essência, a ADPF tinha por objeto verificar se os crimes de tortura e de desaparecimento forçado eram crimes políticos. Por maioria, o STF julgou improcedente a ação e entendeu que a Lei da Anistia foi um mal necessário ao desenvolvimento da democracia brasileira. A incompatibilidade da decisão do STF com os preceitos da decisão internacional da Corte Interamericana seria mote para pesquisa própria, embora, diante dos aspectos expostos no Caso Lund, a fundamentação da decisão internacional revele maior prevalência da proteção dos direitos humanos.

Uma das principais características da justiça de transição é o dever do

\footnotetext{
${ }^{4}$ Vale mencionar que o Brasil alegou incompetência da CoIDH em razão do tempo, pois ela somente entra em vigor para o Brasil em 1998. A Corte afastou este argumento ao dizer que o Brasil concordou com o julgamento de violações continuadas e permanentes, mesmo antes do reconhecimento da jurisdição da Corte.
} 
Estado de prestar contas com seu passado. Para o direito à memória em direitos humanos é irrevelante os rostos que formam o governo ou o alinhamento/ideologia política nos contextos históricos. Para o direito internacional, o Estado não muda com a alteração das mãos que exercem o poder (diferença entre reconhecimento de governo e reconhecimento de Estado), apesar das vicissitudes, continua sendo o mesmo sujeito de deveres.

$\mathrm{O}$ direito à memória no Caso Lund se traduz em crítica contundente à justiça de transição adotada pelo Brasil, mas, positivamente, reforça a ideia de soberania estatal relativizada em matéria de direitos humanos, além de legitimar a existência cada vez mais imprescindível dos órgãos com jurisdição internacional (civil e penal).

As relações entre países eram explicadas pela Lógica de Westfália, concebida pelos tratados firmados em 1648 ao final da Guerra dos Trinta Anos. Ela consolidava uma sociedade internacional formada por Estados soberanos, os quais eram absolutamente livres para decidirem questões domésticas e para entrarem em acordos voluntários, regulando as relações externas com outros Estados (LAFER, 1982, p. 69-71). Eles possuíam todo o poder para resolver aspectos relativos à sua população, ao seu território e a tudo o que ocorresse dentro de suas fronteiras, sem interferência dos demais Estados.

Os principais fatores que concorreram nessa flexibilização da Lógica de Westfália foram a desigualdade de fato entre os Estados e o transnacionalismo. $\mathrm{O}$ primeiro assegurou as condições necessárias à crescente cooperação intergovernamental, enquanto o segundo evidenciou que as relações já não ocorreriam com exclusividade através dos canais diplomáticos, mas, também, pela mediação de instituições multilaterais. A necessidade de regulamentar as relações entre os Estados decorre do reposicionamento do ser humano na centralidade dos debates sociais. No âmbito jurídico, esse movimento pode ser encabeçado pelo princípio democrático e pelo princípio da dignidade humana, este bastante trabalhado na doutrina brasileira. O princípio constitucional da prevalência dos direitos humanos nas relações internacionais nasce do direito internacional construído na primazia das normas de direitos humanos situadas no núcleo duro e no jus cogens.

Embora o contexto atual tenha significado uma maior participação do Estado na ordem internacional e, consequentemente, uma maior ingerência de entes internacionais nos fatos que antes eram considerados exclusivamente domésticos, é preciso ressaltar que ainda há imenso hiato entre o discurso do Estado diante desses organismos e a realidade. Veja-se o exemplo da posição apresentada pela 
representação brasileira no Conselho de Segurança das Nações Unidas em 2004 (outubro sob o título "Justiça e as normas de direito: o papel das Nações Unidas", ocasião em que o Brasil ocupava o assento de membro não-permanente.

De acordo com o posicionamento do Brasil, ele diz aderir à responsabilidade de incutir, defender e restaurar o maior respeito pelo Estado de Direito, internamente e em todo o mundo. Em particular, todos os Estados-Membros têm os deveres indiscutíveis e imperiosos de respeitar a Carta das Nações Unidas e, no presente caso, o direito internacional dos direitos humanos, o direito internacional humanitário, o direito internacional dos refugiados e o direito internacional criminal. Nas operações de paz multidimensionais, a ONU desempenha papel importante na formulação e implementação de iniciativas de pós-conflito a longo prazo, não só para o desenvolvimento e a democracia, mas também em relação ao reforço do Estado de Direito. A adesão ao Estado de Direito implica a observância dos princípios da igualdade perante a lei, a separação de poderes, a governança democrática e a justiça social, entre outros preceitos fundamentais.

Diz-se, ainda, que o Estado de Direito deve ser consistente com as normas internacionais de direitos humanos. O respeito aos direitos humanos - o curso mais eficaz de estabelecer restrições ao poder governamental e para conter a "tirania da maioria" - é ainda mais imperativo em situações de pós-conflito, em que é urgente a proteção das minorias perseguidas. Sobre o tema da justiça transicional em sociedades pós-conflito, algumas questões-chave devem ser destacadas. É preciso considerar cuidadosamente a regra especial da lei e da justiça às necessidades de cada país. A dinâmica é diferente em cada experiência e combinação diferentes, e mecanismos calibrados serão necessários. Por exemplo, é necessário verificar se a relação entre os Tribunais e as Comissões da Verdade está de acordo com situações específicas. Reparações às vítimas de graves violações dos direitos humanos também constituem elemento essencial, bem como os processos de habilitação. Ao tempo que se tem em conta os direitos e as necessidades das vítimas, deve-se reconhecer e respeitar os direitos dos arguidos. O Brasil apoiou a criação do Tribunal Penal Internacional (TPI), um tribunal permanente e independente, para promover o Estado de Direito e garantir que os mais graves e hediondos crimes internacionais não fiquem impunes. Além disso, a representação brasileira deixa claro que rejeita qualquer endosso de anistia para o genocídio, crimes de guerra ou crimes contra a humanidade.

A violência contra civis é inaceitável para o Brasil que, em razão disso, nega qualquer forma de anistia para quem pratica atos de genocídio, crimes contra a humanidade e crimes contra a paz, mas defende que tais casos devem ser devidamente 
julgados por órgãos competentes. Antes do Estatuto de Roma (1998), o Brasil apoiou a criação de tribunais ad hoc para Ruanda e a antiga Iugoslávia. Atualmente, trabalha no fortalecimento da atuação do Tribunal Penal Internacional. A finalização dos casos julgados pelas cortes ad hoc não deve atender a prazos rígidos, pois corre o risco de, diante do desejo de celeridade, deixar lacunas no processo de reconstrução da esperança na justiça. A prevalência dos direitos humanos e a segurança social constituem o caminho para atingir a paz duradoura. Nesse processo, a cooperação com organismos regionais e locais e a participação da sociedade civil organizada são fundamentais.

Sem dúvida, há contradições. É certo que as necessidades, os valores, os interesses e os objetivos de cada Estado dão o traço da política externa adotada, contudo, pode-se pensar que os atos estatais, balizados pela busca por recursos de poder, são de livre escolha daqueles que o representam. Em referência ao Brasil, a Constituição Federal de 1988 atribuiu esta competência ao Chefe do Poder Executivo (art. 84, VII e VIII). No Brasil, por exemplo, essas relações foram objeto de regulamentação no art. $4^{\circ}$ da Constituição Federal de 1988. Trata-se dos princípios que regem o Brasil rem suas relações internacionais. Acerca dos discursos inócuos sob o ponto de vista da proteção da pessoa humana, retorna-se institivamente às reflexões de Gustav Radbruch. Ele afirmou que: "há leis que não são direitos e há um direito acima das leis" e, ainda:

[...] quando nem sequer se aspira a realizar a justiça, quando na formulação do direito positivo se deixa de lado conscientemente a igualdade, que constitui o núcleo da justiça, então não estamos diante de uma lei que estabelece um 'direito defeituoso', mas o que ocorre é que estamos diante de um caso de ausência de Direito (Radbruch, 1997, p. 416).

Após ter observado de perto os horrores do holocaustro, Radbruch passou a criticar a visão exclusivamente positivo-formalista do direito. Segundo o autor, foi ela que permitiu a ascensão do nazismo na Alemanha e as suas nefastas consequências. As reflexões citadas são frutos dessa experiência e foram apresentadas em Cinco Minutos de Filosofia do Direito, publicado em 12 de setembro de 1945, em forma de circular dirigida aos estudantes da Universidade de Heidelberg. Ele ainda disse:

[...] Esta concepção da lei e sua validade, que chamamos Positivismo, foi a que deixou sem defesa o povo e os juristas contra as leis mais arbitárias, mais cruéis e mais criminosas. Torna equivalentes, em última análise, o direito e a força, levando a crer que só onde estiver a segunda estará o primeiro (RADBRUCH, 1997, p. 417). 
O positivismo não está em condições de fundamentar com suas próprias forças a validade das leis (RADBRUCH, 1962, p. 35). Um dos desafios do constitucionalismo moderno é a busca pela maior efetivação dos preceitos constitucionais. O princípio da prevalência dos direitos humanos, inserido no referido artigo $4^{\text {o }}$ é tratado de forma "tímida" pelo direito brasileiro. Uma pesquisa preliminar nos julgados do STF revelou que poucas decisões observam a incidência dessa norma expressa no art. $4^{\circ}$ da Constituição Federal. Parece faltar-lhe força correspondente ao seu status constitucional. Isso ocorre em razão da visão ainda ligada à perspectiva administrativista da regulamentação dos princípios das relações exteriores, voltada ao estabelecimento de diretrizes dos atos governamentais e dos procedimentos da política externa do Estado.

\section{CONCLUSÕES}

A questão do Araguaia coloca o direito interno e o direito internacional face a face. Na ordem internacional, a vontade do Estado brasileiro é exercida pelos posicionamentos dos representantes alinhados com a política externa do Poder Executivo Federal, conforme estabelece a Constituição (art. 84, inciso VII). Via de regra, o Brasil apresenta à sociedade internacional uma ideia de como os direitos humanos devem sempre prevalecer. Nessa perspectiva, os direitos humanos seriam sempre universais, indivisíveis, interdependentes e inter-relacionados. As liberdades públicas implicariam prestações estatais e vice-versa. Entretanto, essa postura não foi a mesma adotada no caso Gomes Lund em que, além de não cumprir a sentença condenatória da CoIDH, o Brasil demonstra profunda ambiguidade no discurso de proteção da pessoa humana e de resgate da memória.

Embora o Estado defenda a parceria entre políticas universais e políticas nacionais na tarefa de concretização dos direitos humanos, o que se observou no caso destacado foi um descompasso entre os compromissos que assume na ordem internacional e a efetivação dos direitos em seu território. Não é sem razão afirmar que os Estados não devem ser os únicos responsáveis pela proteção dos seres humanos. Nesse contexto, é cada vez mais relevante o papel desenvolvido pelas Cortes Internacionais de Direitos Humanos. A proteção do direito à memória está inserida dentre os deveres jurídicos do Estado por meio da força das normas cogente da primazia dos direitos humanos.

O caso Gomes Lund é apenas mais um dos que revelam seres humanos despojados dos direitos mais essenciais. A primazia dos direitos humanos pressu- 
põe a construção de ambiência fundada em três pilares principais: desenvolvimento econômico, democracia e resolução pacífica dos conflitos. A primazia dos direitos humanos é postura impositiva a ser adotada pelos Estados e deve ser posta em prática. A democracia, vista como regime de governo no qual a titularidade do poder político, reside nas mãos do povo compõe um dos pilares para o exercício da primazia dos direitos humanos. É esse mesmo povo que exige transparência e clareza quanto aos atos obscuros praticados pelo Estado em períodos de regime autoritário.

A construção da cultura de diálogo que coloca os direitos humanos acima de qualquer outra questão dependerá da atuação do Estado como ente que deve servir ao povo e não mais o contrário. Estado ainda é o principal responsável pela criação dos ambientes de negociação, logo, a ausência de força militar e o fortalecimento do processo de resolução pelo diálogo, da postura construtiva e da boa-fé são imprescindíveis. A impositividade dos direitos humanos recai sobre os Estados e todos os demais atores de direito internacional público (coletividades estatais, movimentos de libertação nacional, insurgentes, ONGs, seres humanos) e o Brasil não pode continuar fugindo de suas obrigações internacionais, praticando um discurso meramente retórico.

\section{REFERÊNCIAS}

ALÁEZ CORRAL, Benito. Nacionalidad, ciudadanía y democracia ¿A quién pertenece la Constitución? Madrid: Centro de Estudios Politicos y Constitucionales, 2006.

ARENDT, Hannah. La crise de la culture: huit exercices de pensée politique. Paris: Gallimard, 2012.

AYRES, Rodrigo Santa Maria Coquilallard Ayres. Dos porões à Corte Interamericana de Direitos Humanos: desafios da Anistia. Disponível em: <http://www.maxwell.lambda.ele. puc-rio.br/16798/16798.PDF> Acesso em: 06 nov 2014.

BERCOVICI, Gilberto. Constituição econômica e desenvolvimento. São Paulo: Malheiros, 2005.

BOBBIO, Norberto. A era dos direitos. 3. ed. Trad. Carlos Nelson Coutinho. Rio de Janeiro: Campus/Elsevier, 2004. 
BRASIL. Ato Institucional $\mathrm{n}^{\circ}$ 1. Disponível em: <http://www.acervoditadura.rs.gov.br/ legislacao_2.htm>. Acesso em: 15 nov. 2014.

BOSON, Gerson de Brito Mello. Constitucionalização do direito internacional. Belo Horizonte: Del Rey, 1996.

BRASIL. A anistia na era da responsabilização: o Brasil em perspectiva internacional e comparada. Brasília: Ministério da Justiça, Comissão de Anistia; Oxford: Oxford University, Latin American Centre, 2011.

BROTONS, Antonio Remiro. La acción exterior del Estado. Madrid: Tecnos, 1984.

CARBONELL, Miguel (ed.). Neoconstitucionalismo(s). 2. ed. Madrid: Trotta, 2005.

CORTE INTERAMERICANA DE DIREITOS HUMANOS. Sentença do Caso Gomes Lund E Outros ("Guerrilha Do Araguaia”) vs. Brasil. 24 nov. 2010.

DALLARI, Pedro. Constituição e relações exteriores. São Paulo: Saraiva, 1994.

DOUZINAS, Costas. O fim dos direitos humanos. São Leopoldo: UNISINOS, 2009.

ESPALIU BERDUD, Carlos. Desarrollos jurisprudenciales y práctica reciente en la jurisdiccion contenciosa de la Corte Internacional de Justicia. Madrid: Dykinson, 2000.

ESPÍNDOLA, Ruy Samuel. Conceito de princípios constitucionais. São Paulo: Revista dos Tribunais, 1999.

FICO, Carlos. Versões e Controvérsias sobre 1964 e a ditadura militar. Disponível em: $<$ http://www.scielo.br/pdf/rbh/v24n47/a03v2447.pdf>. Acesso em: 22 nov. 2014.

GALEANO, Eduardo. As veias abertas da América Latina. São Paulo: L\&PM. [s.d].

GOMES, Luiz Flávio; MAZZUOLLI, Valerio de Oliveira. Crimes da ditadura militar: uma análise à luz da jurisprudência atual da Corte Interamericana de Direitos Humanos. São Paulo: Revista dos Tribunais, 2011.

KYMLICKA, Will. Multiculturalismo Liberal e Direitos Humanos. In: Daniel Sarmento, Daniela Ikawa e Flávia Piovesan (orgs.). Igualdade, diferença e direitos humanos. Rio de Janeiro: Lumen Juris, 2008. 
LAFER, Celso. A internacionalização dos direitos humanos: Constituição, racismo e relações internacionais. Barueri: Manole, 2005.

. Paradoxos e possibilidades. Rio de Janeiro: Nova Fronteira, 1982.

LENGQUIST, Victor. What is an Agreement In International Law? 50 British Yearbook of International Law". In: Voluntary Return from Sweden to Afghanistan: the legality of UNHCR's participation in a tripartite Memorandum of Understanding. p. 30. Disponível em:

$<$ http://www.jur.lu.se/Internet/Biblioteket/Examensarbeten.nsf/0/7474262112327940C1257 4A900328126/\$File/xsmall.pdf?OpenElement>. Acesso em: 19 jan. 2015.

MELLO, Celso D. de Albuquerque. Curso de direito internacional público. 15. ed. Rio de Janeiro: Renovar, 2004. 2v.

MIRANDA, Pontes de. Comentários à Constituição de 1967, tomo I, p. 45. São Paulo: Ed. Revista dos Tribunais, 1970.

Comentários à Constituição de 1967, tomo IV. São Paulo: Ed. Revista dos Tribunais, 1967.

NUNES, Antonio José Avelãs. Industrialização e desenvolvimento: A economia política do modelo brasileiro de desenvolvimento. São Paulo: Quartier Latin, 2005. Cap. 3, 5 e 6.

PEREZ LUÑO, Antonio E. Los derechos fundamentales. 8. ed. Madrid: Tecnos, 2004.

. Temas Claves de la Constitución Española: Los derechos fundamentales. 8. ed. Madrid: Tecnos, 2004.

PINHEIRO, Letícia. Política externa brasileira. Rio de Janeiro: Jorge Zahar, 2004.

RADBRUCH, Gustav. Cinco minutos de filosofia do direito. In: Filosofia do Direito. Tradução de L. C. de Moncada, 6. ed. Coimbra: Armênio Amado Editor, 1997.

. Arbitrariedad legal y derecho supralegal. Buenos Aires: Abeledo - Perrot, 1962.

RAWLS, John. Direito dos povos. Trad. Luís Carlos Borges. São Paulo: Martins Fontes, 2004.

RISTER, Carla Abrantkoski. Direito ao desenvolvimento: antecedentes, significados e consequências. São Paulo: Renovar, 2007. 
RORTY, Richard. Truth and progress: philosophical papers. v. 3. Cambridge: Cambridge University, 1998.

SARLET, Ingo Wolfgang. A eficácia dos direitos fundamentais. 4. ed. Porto Alegre: Livraria do Advogado, 2004.

Dignidade da pessoa humana e direitos fundamentais. 6. ed. Porto Alegre: Livraria do Advogado, 2008.

SARMENTO, George. Pontes de Miranda e a teoria dos direitos fundamentais. Maceió: mimeo. 2005.

Dignidade da pessoa privada de liberdade: proibição da tortura, tratamentos desumanos ou degradantes. In: Liber Amicorum: Homenagem ao Prof. Doutor António José Avelãs Nunes. Coimbra: Coimbra Editora, 2009, p. 325-348.

SEN, Amartya. Desenvolvimento como liberdade. Trad. Laura Teixeira Motta. São Paulo: Companhia das Letras, 2000.

SORTO, Fredys Orlando. La compleja noción de solidariedad como valor y como derecho: La conducta de Brasil em relación a ciertos Estados menos favorecidos. In: Solidariedad y derechos humanos en tiempos de crisis. Madrid: Dykson, 2011. p. 97-124.

. Considerações sobre a primeira Corte internacional de Justiça. In: Solução e prevenção de litígios internacionais. São Paulo: NECIN-CAPES; Porto Alegre: Livraria do Advogado, p. 275-316, 1999.

. A Doutrina Bush das guerras preventivas e o Sistema das Nações Unidas. In: MERCADANTE, Araminta de Azevedo; MAGALHÃES, José Carlos (Orgs.). Reflexões sobre os 60 anos da ONU. Ijuí: Unijuí, 2005, p. 130-163.

. A Declaração Universal dos Direitos Humanos no sexagésimo aniversário. Verba Juris: Anuário de Pós-Graduação em Direito, João Pessoa, ano 7, n. 7, p. 9-34, jan./dez. 2008.

. O projeto jurídico de cidadania universal: reflexões à luz do direito de liberdade. Anuário hispano-luso-americano de derecho internacional, Madrid, vol. 20, p. 103-126, ene./dic. 2011.

. A condição da pessoa humana no Projeto de Código de Direito Internacional Público de Epitácio Pessoa. In: Epitácio Pessoa e a codificação do direito internacional. Porto Alegre: Sergio Antonio Fabris, 2013, p. 133-155. 
SOUZA, Deusa Maria. A angústia sem fronteiras - a reconstrução do mundo dos familiares de desaparecidos políticos do Araguaia (Brasil) e da Argentina: um estudo comparativo. Associação Nacional de História - ANPUH. XXIV Simpósio Nacional de História. São Leopoldo, 2007.

TOMUSCHAT, C. Human Right: Between idealism and realism. Oxford: Oxford University, 2008.

TRINDADE, Antonio Cançado. The legal personality of the individual as subject of international law. Disponível em: <http://www.wcl.american.edu/> Acesso em: 12 ago. 2014.

Princípios do direito internacional contemporâneo. Brasília: Universidade de Brasília, 1981.

VALLADÃO, Haroldo. Democratização e socialização do direito internacional: os impactos latino-americanos e afro-asiáticos. Rio de Janeiro: José Olympio, 1961. 